\title{
Up from the Ape: the Spitzer Hall of Human Origins at the American Museum of Natural History
}

\author{
William E. H. Harcourt-Smith
}

Published online: 31 March 2012

(C) Springer Science+Business Media, LLC 2012

\begin{abstract}
The American Museum of Natural History in New York has a rich history of explaining evolution through its displays and educational programs. For much of this history, there has been a permanent hall dedicated to human evolution and its related disciplines. Different versions of these halls have informed tens of millions of visitors, and today's offering is one of the world's newest, opened in 2007 and named the Anne and Bernard Spitzer Hall of Human Origins. The hall's design is radical in that it starts by giving molecular genetics and the fossil record equal billing and thus provides the visitor with two independent but highly complementary lines of evidence for our own evolution. Other parts of the hall are innovative in that they stress taxonomic diversity in the fossil record as much as the more traditional chronological "story" of human evolution that is usually found in museum exhibits. The hall is also unique in that it incorporates a fully operational teaching laboratory within its architectural footprint, which provides educators with the chance to seamlessly integrate hands-on lab sessions and the surrounding exhibits as teaching aids.
\end{abstract}

Keywords Human evolution · Hominins .

American Museum of Natural History.

Anne and Bernard Spitzer Hall of Human Origins

\footnotetext{
W. E. H. Harcourt-Smith $(\triangle)$

Division of Paleontology, American Museum of Natural History, New York, NY, USA

e-mail: willhs@amnh.org
}

W. E. H. Harcourt-Smith

Department of Anthropology,

Lehman College and the Graduate Center, CUNY,

New York, NY, USA

\section{Introduction and History}

A few years ago, I was lucky enough to assist in the curation of one of the world's newest displays on human evolution, the Anne and Bernard Spitzer Hall of Human Origins (HHO) at the American Museum of Natural History (AMNH) in New York. For a young scholar only a few years out from their Ph.D., it was a terrifically fun and informative experience. Building such a hall involves the coordination of scholars, designers, artists, model makers, educators, independent experts, and a whole host of other specialists. On the more scientific end of things, one has to carefully approach other institutions and scholars to arrange for new material to be acquired, relentlessly check text for factual accuracy, work with preparators to constantly monitor accuracy in models and reconstructions, check media content, and so on. In the process, I learnt the important lesson that there is nothing like having to work on explaining and displaying your own field of specialty to really make you understand why it is relevant to the world at large.

Now that I'm a university professor and regularly teaching, whenever I walk through the hall, I am reminded that however many students I lecture to in my lifetime, the number will always be dwarfed by those who go through that hall each year (the museum draws approximately four million visitors per annum). What also springs to mind is that of the myriad ways that science can be communicated today, museums still hold the power to educate and enlighten in a way that a thousand CD-ROMs, websites, or TV specials could never do. Simply displaying "the real thing" in an elegant and educational way is still one of the strongest ways that science can be conveyed to a broader audience.

In this paper, I shall discuss briefly the arrangement of the hall, how it differs from its predecessors, and how a number of key message about human origins are reflected in core elements of its design and content. 


\section{Building the Hall}

The previous hall at AMNH, the Hall of Human Evolution and Biology, was completed in the early 1990s, and at that time represented a cutting-edge view on human origins. It was rich in specimens, contained some iconic dioramas of hominin reconstructions in natural settings, and had a beautiful section at the end displaying objects from the dawn of symbolic thought in modern humans. In some fields, 15 years or so is a short time in the shelf-life of a permanent exhibition, but the last 20 years has seen a series of astonishing discoveries in the field of human origins, and we subsequently have a somewhat different view of things. In particular, the advent of powerful techniques for delving into the human genome has provided a serious and independent underpinning for the framework of human evolution as derived from fossil specimens. We have also resolved several key debates about the relatedness of humans and living apes. For instance, molecular work has confirmed that humans and chimpanzees are more closely related to each other than to any other living primates, despite the anatomical and behavioral similarities between chimpanzees and gorillas. The split between humans and chimps is also predicted to have happened between five and seven million years (Ma) ago based on assumed rates of mutational change in the genome (see Hodgson and Disotell 2010). At the opening of the old hall, this may have seemed a little on the old side, but to complement these findings we have seen the announcement of at least eight new fossil hominin taxa, five of which are older than four million years, and two of which are at least six million years or older (see HarcourtSmith 2010 for a review). Thus two independent lines of evidence, those of genetics and paleontology, now pointed to a similar period in time when our own lineage emerged.

The old hall had also been found to have an inadvertent affect on how some visitors viewed human evolution. Scott (2010) showed through survey work that the dark-skinned individuals in the diorama of the ape-like Australopithecus afarensis ("Lucy's" species) at the start of the hall, and the nordic-looking Europeans at the end of the hall led to some African American students thinking that part of the course of human evolution was about getting lighter skin. One cannot necessarily predict that such misconceptions will arise, but nonetheless it was an important observation and food for thought in the planning of any future hall.

So how was a new hall to be built incorporating all these new discoveries, and at the same time taking into account important findings about visitor perceptions of human origins? Permanent halls need to be as up-to-date as possible, but they also have to remain relevant for a significant amount of time, potentially a generation and possibly longer. The lead curators (Ian Tattersall and Rob DeSalle) and the hall designer (David Harvey) came up with an innovative plan to radically restructure the visitor experience. The hall would be divided into four sections. The first would deal with the two main, and complementary, lines of evidence concerning our own evolution; those of molecular genetics and the fossil record. This was a bold move and at that time had never been done before in a major museum display of human evolution. It's easy to display fossils; after all, they are real, tangible objects that the visitor can see and sometimes touch. Not so with genes and DNA. They may as well be entirely invisible to the visitor, and so are very hard to display in a meaningful way.

Turning to actual finished product, visitors are greeted with the striking entry motif (see Fig. 1) depicting a human skeleton flanked by our closest living relative on one side (a chimp) and our closest extinct relative on the other (an exquisitely reconstructed Neanderthal skeleton). At this point, visitors can make the choice to go the "molecular" route or the "fossil" route through the first section of the hall. The molecular route introduces some of the core principals of evolution; presents taxidermy models of our closest living relatives, the primates; and explains evolutionary concepts such as homology via interactive tables. One of the most stunning objects in this section is a small series of test tubes on your immediate left as you first enter. The first two contain chemically solidified lumps of human and chimpanzee DNA that one can easily see. The third one contains a tiny sliver that is barely visible but is incredible once you know what it is. It is an amplified piece of Neanderthal DNA extracted from a well-preserved specimen found in Europe. Although it is modest in appearance, when I conduct tours of the hall, whether privately or to large groups, I always find that this astonishes people. The notion of being able to "see" the DNA of something extinct is a powerful one, however small that actual specimen is, and leaves the visitor with a strong sense of the sophisticated tools available to scientists. I think it can also enlighten the visitor about the tremendous possibilities scientists have for delving into our past.

The fossil route introduces concepts of deep time and lays out the evolution of the first primates through to the first apes some 20 million years ago. It explains geological dating methods, stratigraphy and the process of fossilization. It also lays out a framework of the human family tree, discusses how paleoanthropologists search for fossils (via an interactive display) and presents a short film on the science of fleshing out reconstructions of extinct hominin species. The idea was that the visitor would get a brief introduction to our extinct "cousins" in the fossil record, and a methodological summary of how we study human origins as scientists. I think this is a vital component of any exhibition, and yet you often don't see it. Usually, one sees displays of specimens or reconstructions, sometimes with explanations of evolutionary processes, but very little on the science behind them. 
Fig. 1 The entrance to the Anne and Bernard Spitzer Hall of Human Origins. Visitors take the "molecular" route to the left and the "fossil" route to the right (copyright AMNH)

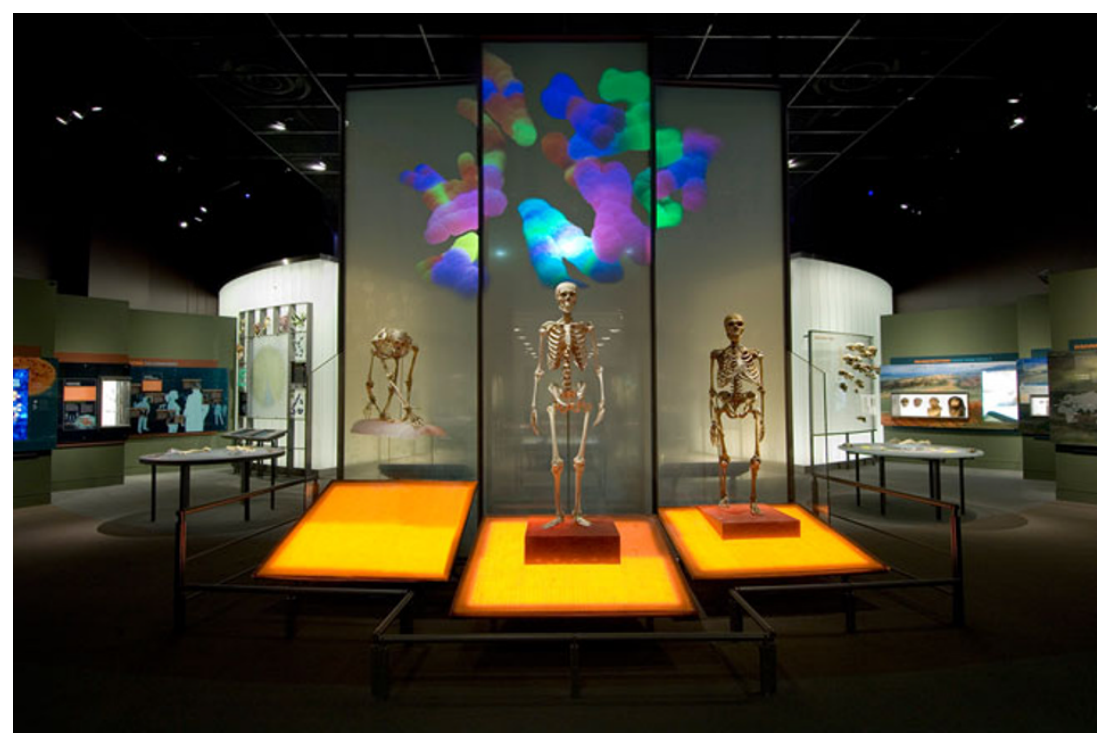

Overall, in this first part of the HHO, there is always the risk of visitors only going one way as opposed to backtracking and doing both, but in fact either route prepares one well for the next section. To my mind, if visitors leave this section of the hall with an understanding of just one or two key concepts (e.g., "we evolved" or "chimps and humans have an ancestor that lived five to seven million years"), one is doing well.

The second section of the hall (Fig. 2) concerns the fossil record and surrounds the visitor with specimens, reconstructions, and information outlining the fossil and archaeological evidence for human evolution. Such temporarily and geographically diverse specimens can sometimes be hard to display in a meaningful way, and the traditional approach has been to have a chronologically linear arrangement of cases. The oldest specimens would be displayed first, and the exhibit would end with modern humans, i.e., "us". In fact, this approach is a common strategy in the depiction and explanation of human origins and can be seen in many

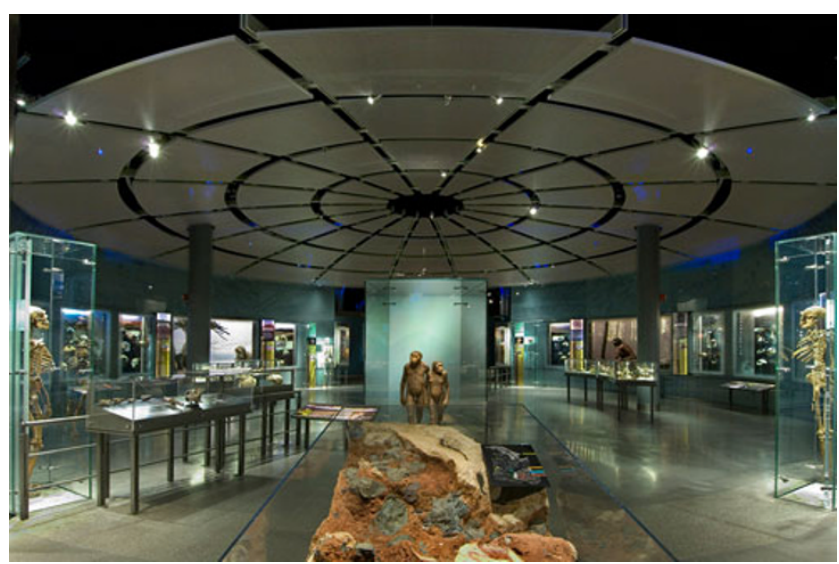

Fig. 2 The circular central section of HHO, which focuses on the fossil and archaeological evidence for human evolution (copyright AMNH) books, television shows, and films about the subject. There is something neat and tidy about it, and as Misia Landau pointed out (1993), in some ways it subconsciously reflects an epic literary narrative. Our "heroes" the hominins have to overcome a series of trials (e.g. discovering fire) throughout their evolution in order to win the day and become modern humans. There's nothing necessarily wrong with a purely chronological approach, but these days the wealth of new fossils discovered in the last 30 years has meant that the human evolutionary tree is far more like a bush than a straight line, with many side branches and dead ends.

At HHO the approach was subsequently very different and somewhat revolutionary. One is greeted by two of the AMNH's most iconic figures recycled from the previous hall, an $A$. afarensis couple making the 3.7-million year footprints at Laetoli, Tanzania. The visitor is then entirely surrounded by fossils, artifacts, and tableaus of hominin reconstructions within a circular space. There is a suggested route they can travel that is roughly chronological, but the overarching feeling is one of immersion. This is important as it allows visitors to explore the taxonomic diversity of our lineage without being forced to treat it in an overtly linear way. You can wander across the space from early African Homo ergaster, to the far later Neanderthals of Eurasia. On the other hand, one can walk along cases on one side of the hall and travel through time from older to more recent specimens. I have to say that I think that this section is a particular strength of HHO. The chronological aspect of human evolution is not ignored (it mustn't be) but it is not driving the average visitor's journey through the evidence. The concept of diversity in our lineage's past is given equal footing, and I think the hall is stronger for it.

This section of the hall is also an excellent example of how scientists, educators, and the exhibits team interacted to create the finished product. For instance, for particular fossil 


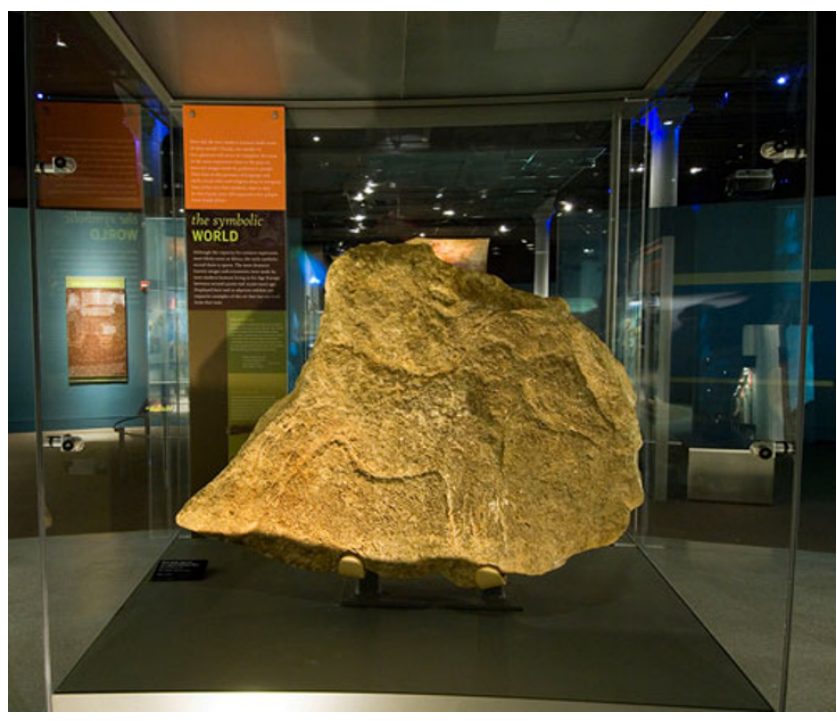

Fig. 3 An original piece of Paleolithic sculpture (of a horse) from Europe heralds the third section of the hall (copyright AMNH)

hominins, there are photographs of fleshed-out reconstructions on the accompanying label decks. These reconstructions were conducted at the AMNH using the latest forensic techniques, and involved constant interaction between the curatorial staff and the artists who created them. It was an informative experience for both sides, and the end results were both scientifically accurate and aesthetically attractive. Such interactions were a strong reminder that where possible, doing things "in-house" has a terrific advantage over outsourcing.

The third section of the hall is the smallest and deals with the emergence of modern humans and their subsequent dispersal across the planet. It also highlights the emergence of symbolic behavior, and the section is fronted by a real specimen of cave-art from the museum's collections (Fig. 3). Given that nearly all specimens in the hall are casts or replicas, this is one of the most powerful objects in the whole space. We also placed a screening area in this section with accompanying interactives, and our Science Bulletins team regularly posts short films on current topics and discoveries in human evolution.

The final section of the hall focuses on how we define modern humans and explores such attributes as tool-use, art, and language. The idea was to explore these different themes and see whether the differences between humans and other animals was absolute or merely one of degree. The message is particularly strong with something like toolmaking, where we know that some chimpanzees can make quite complex tools, and that the line between us and them is very blurred. The section ends with, in my opinion, two very important parts of the hall. There is a video of leading scientists from around the world talking about their views on faith and evolution. This may seem strange for an evolution exhibit in New York, but we attract visitors from across the globe, some of whom may have fairly conservative views. Rather than provide a confrontational approach by telling people that they have to choose between faith and science, the video depicts scientists discussing how it is acceptable to firmly know that humans evolved based on the evidence to hand, but that this didn't necessarily preclude the existence of a deity. HHO is not an exhibit about faith, but at the same time it is important to not try and push a scientific viewpoint in an evangelical manner, and to be as inclusive as possible. I think this particular interactive strikes an excellent balance in a potentially tricky area. The hall ends with a discussion on the future of human evolution. One of the most common questions I get, whether in class or from people I meet, is: "are we still evolving." It's a natural thing to ask, and even though the answers have to be somewhat speculative in nature, it's important to discuss it in any display on human evolution.
Fig. 4 Inside the Sackler Educational Laboratory for Comparative Genomics and Human Origins (copyright AMNH)

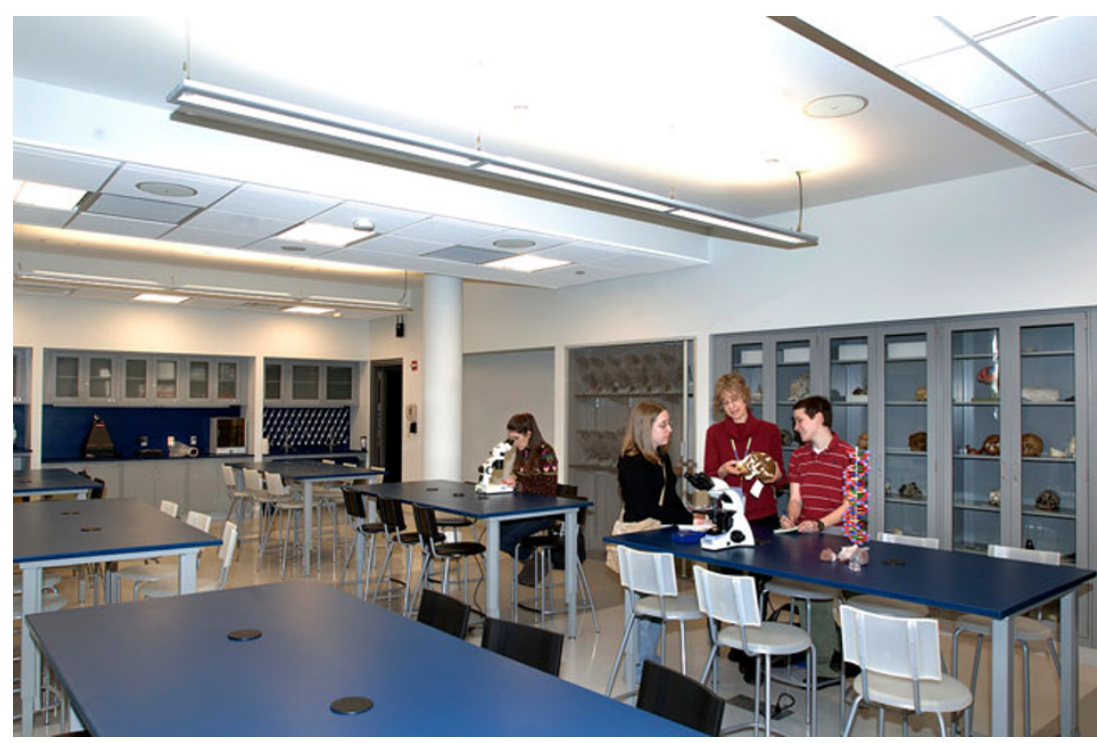




\section{The Sackler Educational Laboratory}

One of the most important and dynamic components of the hall is the Sackler Educational Laboratory for Comparative Genomics and Human Origins (Fig. 4). The HHO is one of the only permanent exhibitions in the world to include a fully integrated teaching laboratory within its architectural footprint. Such educational spaces in museums are usually in discrete locations often far removed from the objects and the subject matter they are addressing. With the Sackler Lab, students and visitors retain the immersive experience of being physically surrounded by the evidence for human origins while engaging in educational activities in the lab itself. It also acts as an excellent way to better integrate the educational goals of the museum in relation to human evolution. Educators and experts can seamlessly use the hall as a teaching aid during labs, whether in a more formal and didactic way, or in a more indirect way where students can "dip in" to the hall to answer specific questions during an exercise. In my opinion, this is an excellent model for future halls, whatever their focus.

\section{Interactives}

We were also careful to have a number of interactive displays strategically placed throughout the hall. The idea of these was to enhance the visitor's experience of human origins in an age when multimedia plays a significant role in everyday life. The core of what museums are rests on the objects that they display, but thoughtfully placed interactive displays can enhance the experience, and in some cases greatly help in getting across complex themes, especially to a younger audience. With HHO, we tried to link interactives to content nearby in the hall. In the first section of the hall, for instance, we had one interactive explaining the genetic "Tree of Life" on the "molecular" side of the hall, and one explaining the process of discovering fossils on the "fossil" side of the hall. A third display allows visitors to explore both DNA and fossil specimens in ever increasing powers of magnification. In all cases, the interactives used state-of-the-art scientific findings and techniques, many of which were being used at the museum as part of ongoing research.

One small problem that has emerged with $\mathrm{HHO}$ is the proximity of some interactives to each other. In one part of the hall, we have two of the same interactives next to each other, and a narrated film projection close by. The result is that you can sometimes have three competing audio narrations running at the same time. We have observed that this can make it difficult for the visitor (especially children) to concentrate on the particular interactive they are looking at. It's an important reminder that thought should be given to the adequate spacing of interactives with audio content.

\section{Final Thoughts}

There are obviously key concepts that one has to get across when developing a human evolution display or hall. Visitors should be able to understand the timescale over which human evolution occurred and understand how we attain geological dates. They should leave knowing at least a few of the particular features that define extinct hominin species, and they should understand that our place is firmly in nature, as for all other organisms. They should also know what defines us as human and realize that some of the differences between us and other primates are not absolute but merely a matter of degree.

However, I think it is also important to take a step back and consider what one truly wants to get across as a key concept, and what angle(s) one wants to take in order to do that. Halls such as HHO often convey a subtle but distinct overlying theme. For instance, the new Hall of Human Origins at the Smithsonian Institution's Museum of Natural History in Washington D.C. particularly emphasizes the relationship between human evolution and environmental change. As I discussed above, the core themes at AMNH are very different, and there is a strong emphasis on the taxonomic diversity found throughout our lineage, as well as the role of molecular genetics in the study of human evolution. Both these institution's particular approaches are very worthy lenses through which to highlight human origins, and remind us that there are many ways to approach the subject as an exhibition team. That is not to say that either of these exhibits ignore the themes that the other emphasizes, but there are nonetheless distinct differences in flavor.

I personally think that this is an important point to highlight; human evolution is a complex affair, and there are many angles that one can approach it from. One cannot use all of them of course, as it would overcomplicate things for the visitor, and anyway, it would be a boring world if all human evolution exhibits were the same.

Acknowledgments I would like to thank Monique Scott for inviting me to submit this paper to this special issue of $E: E \& O$.

\section{References}

Harcourt-Smith WEH. The first hominins and the evolution of bipedalism. Evolution: Education and Outreach. 2010;4(3):333-40.

Hodgson JH, Disotell T. Anthropological genetics: inferring the history of our species through analysis of DNA. Evolution: Education and Outreach. 2010;4(3):387-98.

Landau M. Narratives in human evolution. New Haven: Yale Press; 1993.

Scott M. The pleasures and pitfalls of teaching human evolution in museums. Evolution: Education and Outreach. 2010;4(3):403-9. 